\title{
A RARE FAMILIAL CASE REPORT OF NAIL-PATELLA SYNDROME
}

\section{Rakesh Bayyavarapuํㅜ, Kiran Raju Nandyala², Venkateshwar Rao S³, Sindhura Nadella4, V. N.} Narvekar ${ }^{5}$

\section{HOW TO CITE THIS ARTICLE:}

Rakesh Bayyavarapu, Kiran Raju Nandyala, Venkateshwar Rao S, Sindhura Nadella, V. N. Narvekar. "A Rare Familial Case Report of Nail-Patella Syndrome". Journal of Evolution of Medical and Dental Sciences 2014; Vol. 3, Issue 55, October 23; Page: 12695-12701, DOI: 10.14260/jemds/2014/3683

ABSTRACT: Nail-patella syndrome is a rare genetic disorder, which is inherited as an autosomal dominant trait. This condition is also known as hereditary osteo-onychodysplasia (HOOD syndrome), Fong's syndrome, Turner-Kieser syndrome.(1) Posterior iliac horns are commonly found in this syndrome and are considered pathognomonic. In this case report we have described almost all the radiographic features of nail-patella syndrome including the pathognomic iliac horns and other skeletal features including absent or hypoplastic patellae, elbow abnormalities, as seen on radiographs. The magnetic resonance imaging (MRI) of the features of this syndrome has been mentioned in only one report,(2) however, no images were actually presented. Considering the hereditary nature (autosomal dominant) of the syndrome we wanted to rule out whether any other member in the family are involved and to our surprise we found two other members(mother and elder brother) in the family with similar features.

KEYWORDS: Nail-Patella syndrome, hereditary onycho-osteodystrophy, fong's syndrome.

INTRODUCTION: Nail-patella syndrome (NPS), which is also known as hereditary osteoonychodysplasia or Fong's syndrome, is a hereditary disorder with an autosomal dominant trait. This condition is caused by mutations in the LMX1B gene (3) and has a very low incidence of about 4.5 per million ${ }^{(4)}$ and prevalence ${ }^{[5]}$ at $1 / 50000$.These mutations of the LMX1B gene located at the distal end of long arm of chromosome 9q34. Studies have been conducted and 83 mutations of this gene have been identified in this gene. $(6,7,8)$

More than 140 heterozygous mutations in LMX1B have been reported,[9] including missense, splicing, deletions, and nonsense mutations. Most mutations are located in the LIM domains. Most mutations are located in the LIM domains. ${ }^{[10]}$ Although there is a phenotypic variability within families, the nephropathy is more often associated with homeodomain mutations.[11,12]

The condition affects the nails, skeletal system, kidneys, and eyes.(13) The skeletal features include absent or hypoplastic patellae, patellar dislocations, elbow abnormalities, talipes, and iliac horns as seen on radiographs. These iliac horns are considered to be pathognomonic feature of NPS. In an autopsy study by Darlington and Hawkins(14) the localization of the iliac horns in NPS was determined to be at the site of attachment of the gluteus medius muscles.

Nail-patella syndrome is defined by the following major Features[15]: Nail anomalies- in 80-90\% of patients they are bilateral and symmetrical; nails can be absent, hypoplastic, or dystrophic (discolouration, triangular lunulae, splitting, ridging, and thinning). Skeletal anomalies- the most frequent are: absent or hypoplastic patellae, iliac horns (pathognomic), dysplastic elbows. Rarely genu recurvatum, genu varum, genu valgum, hypoplasia of cruciate ligaments, pectus excavatum, scoliosis, increased lumbar lordosis, spondylolisthesis, spondylosis, spina bifida, etc. 
Other extra skeletal features include glaucoma, attention deficit disorder, depression, lean habitus and difficulty to gain weight, gastrointestinal symptoms (irritable bowel, syndrome constipation).

Renal disease(16) includes found in approximately $40 \%$ of patients: microscopic hematuria, proteinuria, hypertension progression to renal failure has been reported in $3-15 \%$ of Nail-patella syndrome patients.

CASE REPORT: A 12 year old male child presented to the orthopaedic outpatient clinic with flexion deformity of bilateral elbows. He was functionally impaired and had difficulty participating in sporting activities.

The parents gave history of full term, normal delivered child, with mild deformity and contractures at bilateral ankle regions at birth which were relieved with surgery.

On examination of nails, dystrophic changes involving several finger nails were noted predominantly involving thumbs and index finger of both the hands.

On examination of knees, there was complete bilateral absence of patellae. Femoral condyles are large and prominent with sulcus in between condyles.

Radiographs of both knees (AP and Lateral) showed absence of both patellae and mild genu valgum deformity. Skyline view of both knee joints showed absence of bilateral patella.

Radiograph of pelvis (AP) showed bilateral iliac horns suggestive of iliac fongs.

Both elbow joints AP and Lateral showed absence/hypoplastic proximal epiphysis (head) of radius with mild posterolateral subluxation of radial head in both elbow joints.

Considering the hereditary nature (autosomal dominant) of the syndrome we wanted to rule out whether any other member in the family had similar features.

To our surprise patient's mother (40 years) and elder brother (13yrs) had similar features with absent/hypoplastic patella on examination and even dysplastic finger and toe nails which are depicted in the clinical photographs.

Radiograph of knee showed hypoplastic patella for both mother and elder child with lateral subluxation of patella in skyline view of patella.

Radiograph of both elbows AP and lateral showed hypoplastic radial head and posterolateral subluxation of radius in both elbow joints.

Magnetic resonance imaging was done for the mother to exactly delineate the iliac horns and their anatomical relationship with surrounding structures.

MRI clearly revealed cortical and medullar components of the iliac horns, and their continuity with the corresponding posterolateral aspect of iliac bones. The iliac horns were shown to be located at the insertions of gluteus muscles; however, the kidneys were morphologically normal. Considering the pathognomonic finding of iliac horns and the presence of the associated features, the patient was diagnosed as Nail-Patella Syndrome.

DISCUSSION: Nail-patella syndrome is characterized by clinical trial involving the nails, skeletal system, and renal system. Although the diagnosis of nail patella syndrome can be established in early infancy through the radiographic demonstration of iliac horns, this disorder is rarely diagnosed in infancy. This is because the abnormalities of the nail and patella, which are essential for diagnosis, may not become apparent until later in life. The nails can be absent, hypoplastic, or dystrophic. 
These abnormalities present in $80-90 \%$ of patients. These abnormalities are often bilateral and symmetrical with more severely affecting thumb nails and least severity in little fingers. Dysplasia of toe nails is less frequent. Diminished skin creases over the distal inter-phalangeal joints of affected fingers are common. Most common skeletal affection is hypoplastic or absent patella.

Sometimes patella displaced or dislocated. Abnormalities of elbows may be asymmetric presenting with radial head and lateral epicondyle hypoplasia, causing subluxation of the radial head. Pathognomic radiological features of iliac horns are present in 30-70\% of patients.[17]

Extra-skeletal manifestations involving the kidneys ${ }^{[18]}$ affects up to $40 \%$ of individuals, whereby $3-15 \%$ progress to end stage renal disease. Often, patients present with proteinuria with or without haematuria and may remain asymptomatic.

Other manifestations are primary open-angle glaucoma and ocular hypertension, cloverleaf pigmentation of the iris (Lester's sign), attention-deficit hyperactivity disorder, sensory neuropathy, sensorineural hearing loss, irritable bowel syndrome and chronic constipation. Genetic studies were not performed in our patient as the diagnosis of Nail-patella syndrome was established based on the clinical and radiological manifestations.

CONCLUSION: Many patients with NPS seek medical attention for seemingly unrelated pathologies. In many instances, the radiologist may be the first to make the clinical diagnosis based on the findings from the imaging examinations. Moreover, early diagnosis is of particular importance in infants, because nail and patellar abnormalities may be overlooked during the first few years of life and may not be obvious until childhood. If the diagnosis of NPS is indicated, the presence of the iliac horns can confirm this syndrome. It serves as a platform to understand and diagnose patients with presentation of abnormal nails and skeletal development. Future studies such as genetic therapy may have a role in reducing skeletal morbidity and reduce the risk.

\section{REFERENCES:}

1. James, William; Berger, Timothy; Elston, Dirk (2005). Andrews' Diseases of the Skin: Clinical Dermatology. (10th ed.). Saunders. Page 786-7.

2. Karabulut N, Ariyurek M, Erol C, Tacal T, Balkanci F. Imaging of "iliac horns" in nail-patella syndrome. J Comput Assist Tomogr 1996; 20: 530-1.

3. Marini M, Bongers EM, Cusano R, et al. Confirmation of CLIM2/LMX1B interaction by yeast twohybrid screening and analysis of its involvement in nail-patella syndrome. Int J Mol Med 2003; 12: 79-82.

4. Goshen E, Schwartz A, Zilka LR, Zwas ST. Bilateral accessory iliac horns: pathognomonic findings in Nailpatella syndrome. Scintigraphic evidence on bone scan. Clin Nucl Med 2000; 25: 476-7.

5. Levy M, Feingold J. Estimating prevalence in single-gene kidney diseases progressing to renal failure. Kidney Int. 2000; 58: 925.

6. Sweeney E, Fryer A. "Nail patella syndrome: a review of the phenotype aided by developmental biology". Journal of Medical Genetics 40 (3): 153-162.

7. Towers AL, Clay CA, Sereika SM, McIntosh I, Greenspan SL (April 2005). "Skeletal integrity in patients with nail patella syndrome". J. Clin. Endocrinol. Metab. 90 (4): 1961-5. 
8. Romero P, Sanhueza F, Lopez P, Reyes L, Herrera L (2011) c.194 A>C (Q65P) mutation in the LMX1B gene in patients with nail-patella syndrome associated with glaucoma. Mol Vis 17:1929-1939

9. Hamlington JD, Jones C, McIntosh I. Twenty-two novel LMX1B mutations identified in nail patella syndrome (NPS) patients. Hum Mutat 2001; 18: 458.

10. Dreyer SD, Zhou G, Baldini A, et al. Mutations in LMX1B cause abnormal skeletal patterning and renal dysplasia in nail patella syndrome. Nat Genet 1998; 19: 47.

11. Knoers NV, Bongers EM, van Beersum SE, et al. Nail-patella syndrome: identification of mutations in the LMX1B gene in Dutch families. J Am Soc Nephrol 2000; 11: 1762.

12. Bongers EM, Huysmans FT, Levtchenko E, et al. Genotype-phenotype studies in nailpatella syndrome show that LMX1B mutation location is involved in the risk of developing nephropathy. Eur J Hum Genet 2005; 13: 935.

13. Sweeney E, Fryer A, Mountford R, Green A, McIntosh I. Nail patella syndrome: a review of the phenotype aided by developmental biology. J Med Genet 2003; 40: 153-62.

14. Darlington D, Hawkins CF. Nail-patella syndrome with iliac horns and hereditary nephropathy. Necropsy report and anatomical dissection. J Bone Joint Surg Br 1967; 49: 164-74.

15. Little EM. Congenital absence or delayed development of the patella. Lancet 1897; 2:781.

16. Hawkins CF, Smith OE. Renal dysplasia in a family with multiple hereditary abnormalities including iliac horns. Lancet 1950; 1: 803.

17. Lucas GL, Opitz JM, Wiffler C. The nail patella syndrome. Clinical and genetic aspects of 5 kindreds with 38 affected family members. J Pediatr 1996; 68: 273-88.

18. Looij BJ Jr, te Slaa RL, Hogewind BL, van de Kamp JJ. Genetic counseling in hereditary osteoonychodysplasia (HOOD, nail-patella syndrome) with nephropathy. J Med Genet 1988; 25: 682-6.

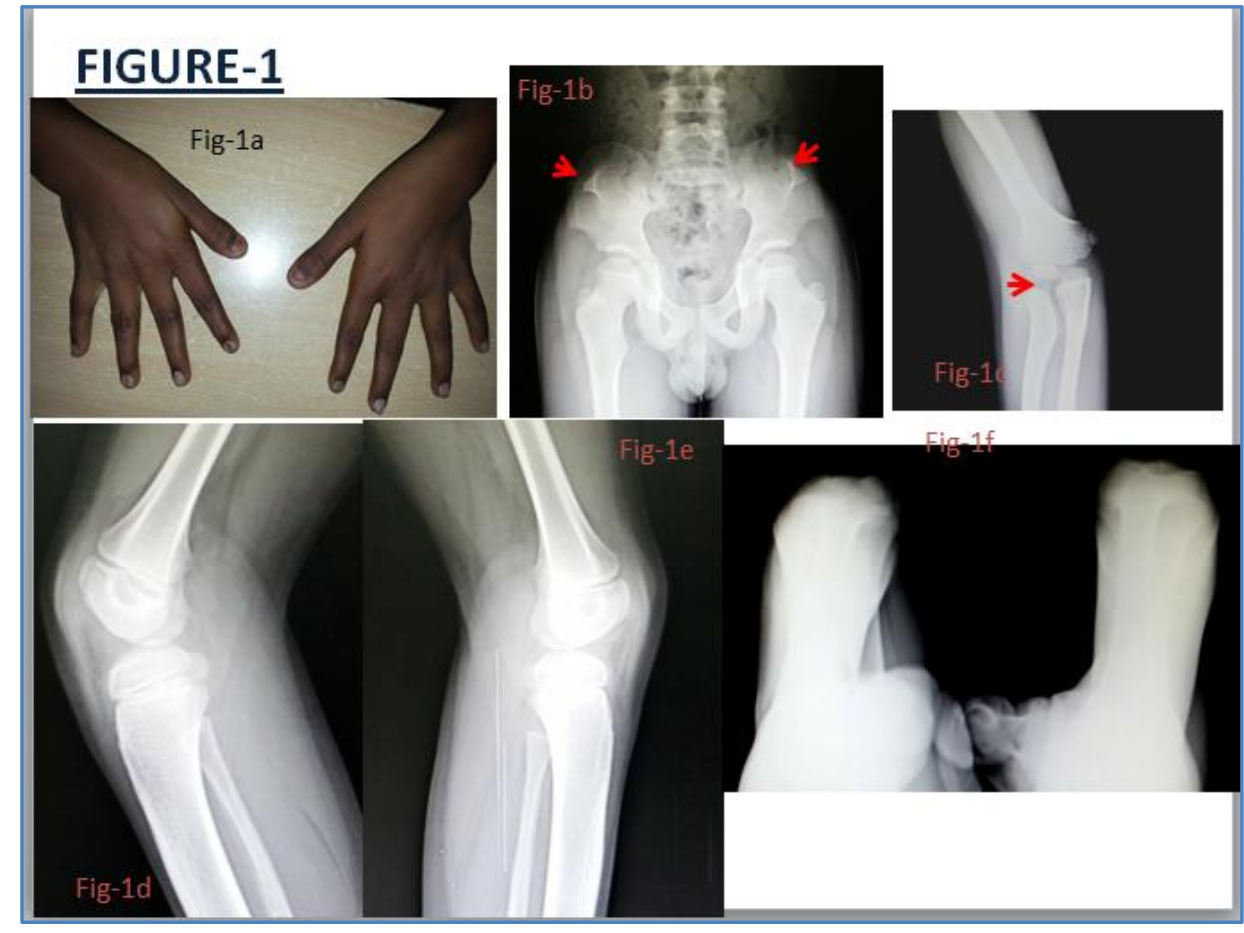


FIGURE-1: These are the images of 12 year old child who actually came to orthopaedics OPD.

Fig-1a: Ridging, splitting and hypoplastic finger nails predominantly involving thumb and index finger.

Fig 1b: AP radiograph of pelvis with both hips showing iliac horns.

Fig 1c: AP radiograph of elbow showing hypoplastic proximal radial epiphysis (head of radius) with lateral subluxation of radius.

Fig 1d \& 1e: Lateral radiograph of right and left knee joints showing absent patella.

Fig 1f: Skyline view of both knee joints confirming the absence of patella bilaterally.

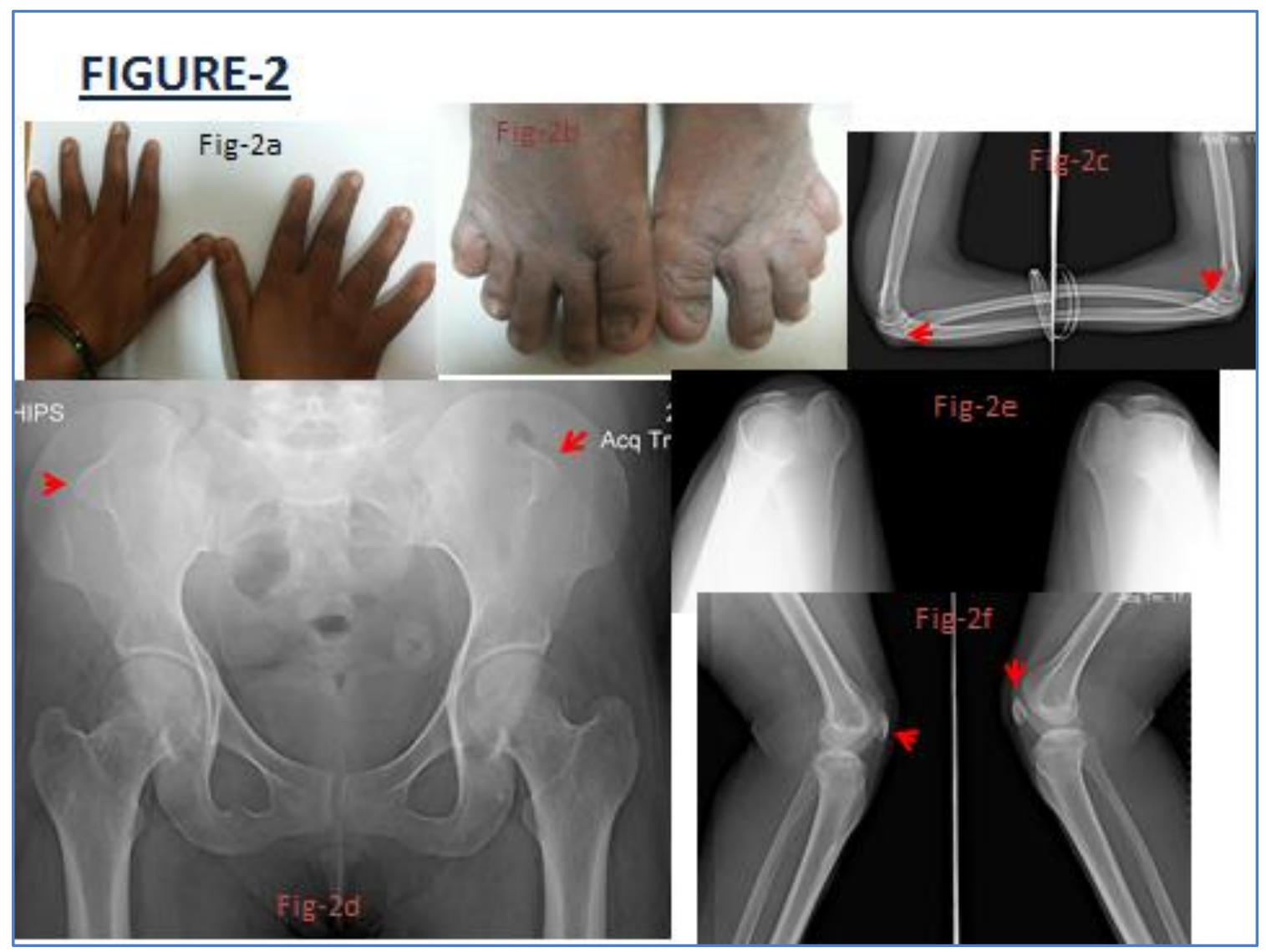

FIGURE-2: These are the images of mother of the patient who also showed features of Nail Patella Syndrome.

Fig $2 \mathrm{a}$ and 2b:- Clinical photographs of the hand and foot showing hypoplastic nails in thumb and great toe.

Fig 2c: Lateral radiograph of both elbows shows hypoplastic radial head bilaterally.

Fig 2d: AP Radiograph of pelvis with both hip joints showing bilateral iliac horns.

Fig 2e: (skyline view) and lateral radiograph of both knee joints showing hypoplastic patella. 


\section{CASE REPORT}

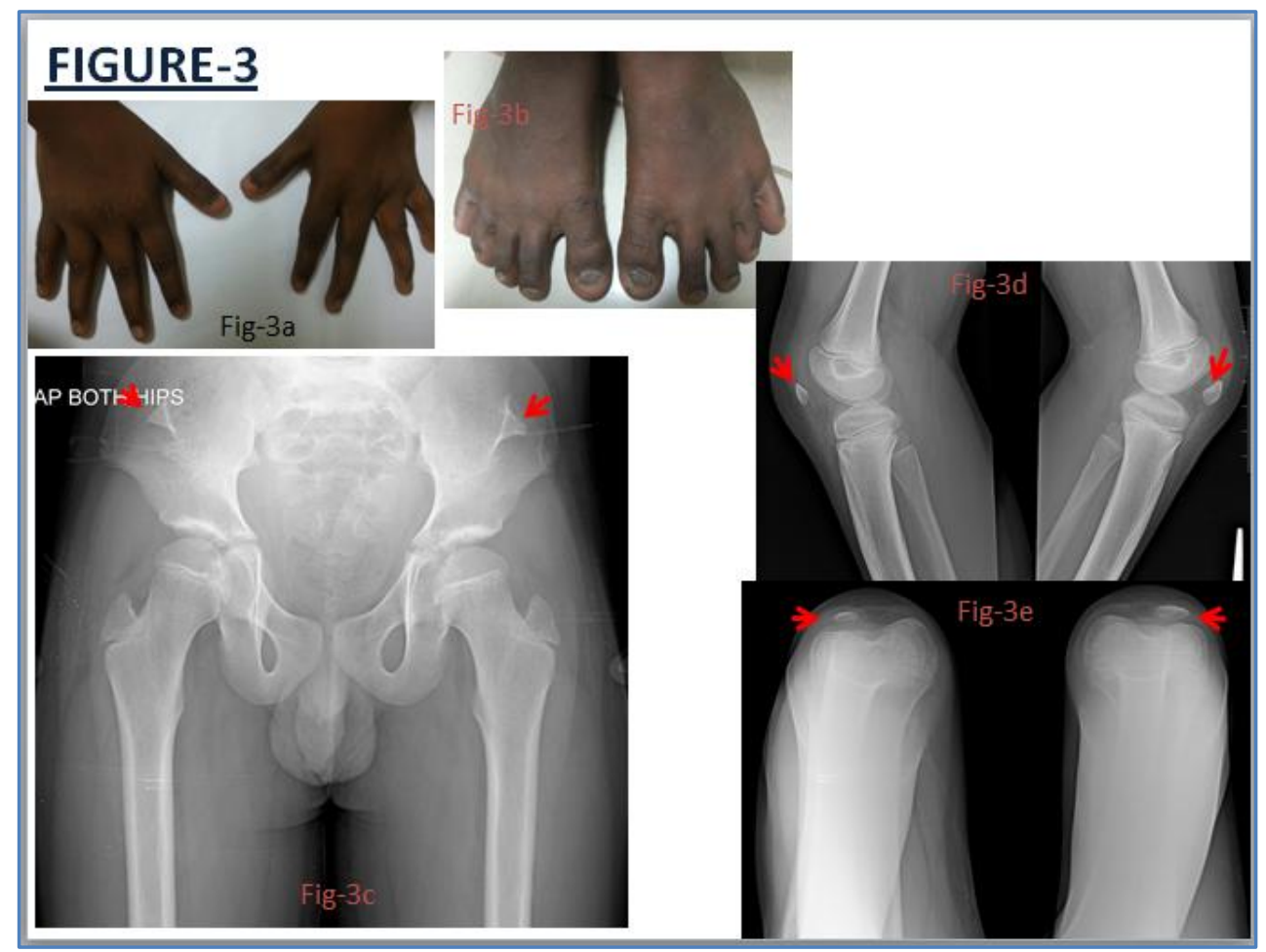

FIGURE-3: These are the images of elder brother of the patient who also showed features of Nail Patella Syndrome.

Fig 3a and 3b:-Clinical photographs of the hand and foot showing hypoplastic nails in thumb and great toe.

Fig 3c:- AP radiograph of pelvis with both hip joints showing bilateral iliac horns.

Fig 3d (skyline view) and Fig 3e (Lateral radiograph of both knee joints) showing hypoplastic knee joints with minimal lateral displacement.

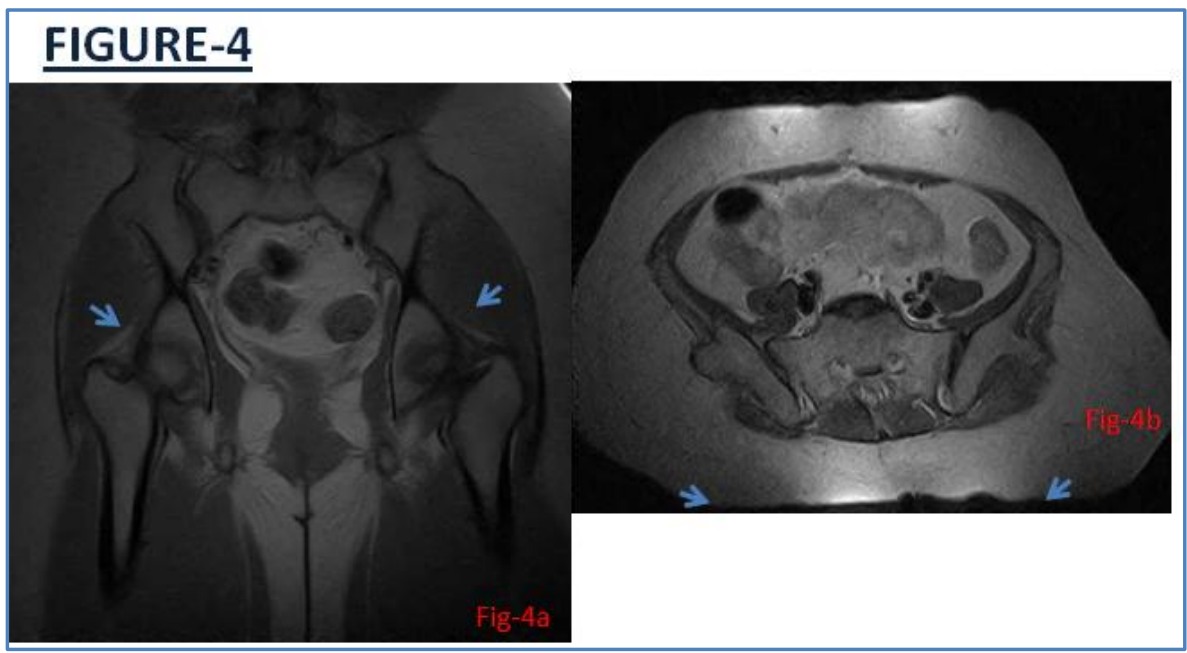

Figure-4: MRI T1W coronal (Fig 4a) and axial (Fig 4b) of the mother showing bilateral iliac horns both arising posterolaterally between the iliac bone and gluteus medius muscle. 


\section{CASE REPORT}

\section{AUTHORS:}

1. Rakesh Bayyavarapu

2. Kiran Raju Nandyala

3. Venkateshwar Rao S.

4. Sindhura Nadella

5. V. N. Narvekar

\section{PARTICULARS OF CONTRIBUTORS:}

1. Assistant Professor, Department of Radiodiagnosis, ASRAM Medical College, Eluru, Andhra Pradesh.

2. Assistant Professor, Department of Radiodiagnosis, ASRAM Medical College, Eluru, Andhra Pradesh.

3. Associate Professor, Department of Radiodiagnosis, ASRAM Medical College, Eluru, Andhra Pradesh.

4. Assistant Professor, Department of Radiodiagnosis, ASRAM Medical College, Eluru, Andhra Pradesh.
5. Professor and HOD, Department of Radiodiagnosis, ASRAM Medical College, Eluru, Andhra Pradesh.

\section{NAME ADDRESS EMAIL ID OF THE CORRESPONDING AUTHOR:}

Dr. B. Rakesh,

Assistant Professor,

Department of Radiodiagnosis,

ASRAM Medical College,

Eluru-534005, West Godavari District,

Andhra Pradesh.

Email: rajkiren@gmail.com

Date of Submission: 15/10/2014.

Date of Peer Review: 16/10/2014.

Date of Acceptance: 20/10/2014.

Date of Publishing: 23/10/2014. 